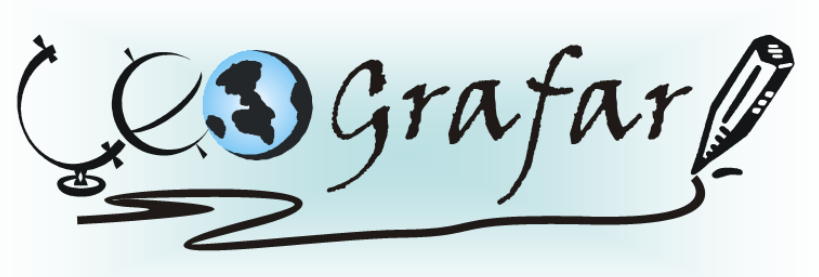

Revista Eletrônica do Programa de Pós-Graduação em Geografia - UFPR

\title{
RELAÇÃO ENTRE SOLO E CLIMA NO RIO GRANDE DO SUL, SEGUNDO DIFERENTES MODELOS EDAFOCLIMÁTICOS
}

\section{RELATIONSHIP BETWEEN SOIL AND CLIMATE IN RIO GRANDE DO SUL ACCORDING TO DIFFERENT EDAFOCLIMAPHY MODELS}

\author{
(Recebido em 22.03.2012; Aceito em 19.01.2013)
}

Elsbeth Léia Spode Becker Professora Adjunta da Área de Ciências Humanas Centro Universitário Franciscano - UNIFRA

Santa Maria, RS, Brasil e-mail: elsbeth.geo@gmail.com

Galileo Adeli Buriol Professor Titular da Área de Ciências Naturais e Tecnológicas Centro Universitário Franciscano - UNIFRA Bolsista do CNPq Santa Maria, RS, Brasil e-mail:galileo@unifra.br

Nereu Augusto Streck Professor Titular do Departamento de Fitotecnia de Ciências Rurais Universidade Federal de Santa Maria Bolsista do CNPq

Santa Maria, RS, Brasil e-mail: nstreck1@gmail.com

\section{Resumo}

Estudou-se a relação dos solos do Rio Grande do Sul com as disponibilidades climáticas regionais, por meio de modelos edafoclimáticos. Foram utilizadas as médias anuais de radiação solar global de 25 estações meteorológicas, período 1950-1984, pertencentes à Fundação Estadual de Pesquisa Agropecuária (FEPAGRO) e a temperatura média das médias e média das máximas e mínimas anuais do ar e a média dos totais anuais das precipitações pluviais de 41 estações meteorológicas pertencentes ao $8^{\circ}$ Distrito de Meteorologia (8DISME), período 1931-1960. Foram calculados, ainda, para as 41 estações, a evapotranspiração 
potencial e o balanço hídrico. Com estes dados calcularam-se os índices para 7 modelos edafoclimáticos. Estes modelos enquadram o Estado do Rio Grande do Sul como uma região com características de solos com perfis profundos e bem desenvolvidos que podem condicionar uma vegetação natural do tipo bosque. Assim, apenas uma parte da área do Rio Grande do Sul, especialmente aquelas que são mapeadas como sendo de solos Latossolos, Chernossolos, Argissolos e Nitossolos e Argissolos (predominantemente localizados no Planalto NorteRiograndense e na Depressão Central, respectivamente), é explicada em função das disponibilidades climáticas vigentes. Desta forma, concluiu-se que outros fatores, além do clima, devem ser estudados com a possibilidade de aproximar o zoneamento dos solos do Rio Grande do Sul com as disponibilidades climáticas, considerando, especialmente, a topografia e o tempo geológico.

Palavras-Chave: intemperismo, temperatura, precipitação pluvial.

\begin{abstract}
The relationship of the soil of Rio Grande do Sul with the existing regional climate was studied through edafoclimaphy models. The average annual solar radiation of 25 meteorological stations, 1950-1984 period, belonging to the State Foundation of Agricultural Research (FEPAGRO) and the average temperature of the averages, and the average of maximum and minimum annual air as well as the total annual rainfall average of 41 meteorological stations belonging to the 8th District of Meteorology (8th Disma), 1931-1960 period, were used. In addition, the potential evapotranspiration and water balance to the 41 stations were calculated. With these data, indexes for 7 edafoclimaphy models were calculated. These models feature the State of Rio Grande do Sul as a region with characteristics of soil with deep and well developed profiles that can cause a type of natural wood vegetation. Thus, only parts of the area of Rio Grande do Sul, especially those which are mapped as being of Oxisols, Chernosol, Argisols and Nitossolo and Argisols soil (predominantly located in the North-Riograndense Plateau and the Central-Depression, respectively), are explained according to of the current climate. Thus, other factors, besides climate, should be studied with the possibility of approaching the soil zoning of Rio Grande do Sul with to available climate, considering especially the topography and geological time.
\end{abstract}

Keywords: weathering, temperature, rainfall.

\title{
Introdução
}

O clima determina o intemperismo, condicionando as características do solo formado da rocha matriz de distintas composições mineralógicas. No Rio Grande do 
Sul ainda existem poucos estudos que relacionam a formação do solo com o clima por meio da utilização de modelos edafoclimáticos.

Um mesmo tipo de rocha, quando submetida a condições climáticas diferentes, geralmente, se transforma em tipos de solos distintos. Por outro lado, rochas diferentes, quando sujeitas às mesmas condições climáticas, por um logo período de tempo, dão origem, normalmente, a solos semelhantes ou quase idênticos. Os solos zonais, que recobrem vastas áreas da superfície terrestre, refletem esse condicionamento dominante (CHRISTOFOLETTI, 1974). No entanto, o esquema, válido na escala do planeta Terra, pode ser bastante modificado por condições locais, dando origem aos solos intrazonais, que têm sua formação influenciada, principalmente, por fatores locais como relevo, litologia, organismos e vegetação (TEIXEIRA et al., 2003). Assim, a gênese dos diferentes tipos de solos está diretamente relacionada ao intemperismo das rochas da superfície terrestre, provocado pela ação integrada de fatores como material de origem, clima, relevo, vegetação, animais e/ou organismos e tempo (JENNY, 1941). O clima, principalmente pela ação da precipitação pluvial, temperatura, radiação solar, umidade do ar, evaporação e vento, é o fator que atua com maior intensidade no condicionamento dos diferentes tipos de solos (TEIXEIRA et al., 2003).

A idéia de relacionar os solos ao clima é antiga. Nas primeiras tentativas de classificação dos solos, em escala mundial, a distribuição geográfica dos solos corresponde, aproximadamente, com as diferentes zonas climáticas traçadas na carta da superfície terrestre (BUENO, 1984).

Atualmente, a relação existente entre solos e clima continua sendo utilizada, pois, resume as bases para uma ampla apreciação da distribuição geográfica dos solos do mundo e sua relação com os diferentes tipos climáticos no globo, bem como com os grandes biomas de vegetação natural e com o tipo de agricultura (STRAHLER; STRAHLER, 2005).

Segundo Drew (2002), apesar do caráter genérico, a relação entre solo e clima representa um guia global para as amplas variações existentes nos tipos de solos. Considera que os tipos, enumerados como solos zonais, foram divididos em aproximações em que solo, vegetação e clima estão interligados, sendo o clima a causa e os solos e a vegetação os efeitos. 
No Rio Grande do Sul, a relação entre solos e clima é pouco estudada. O clima do Estado, segundo a classificação climática de Köppen (1948), é do tipo Cfa (úmido em todas as estações, verão quente) e Cfb, (úmido em todas as estações, verão moderadamente quente) com chuvas bem distribuídas ao longo dos doze meses do ano (MORENO, 1961; KUINCHTNER et al., 2001). Nesse caso, a precipitação pluvial, a temperatura do ar e a amplitude térmica favorecem a formação de solos profundos. No entanto, há doze classes de solos identificadas e mapeadas (STRECK et al., 2008), distribuídas, geograficamente, de forma bastante heterogênea e com alternância, incluindo, também, solos rasos e pouco desenvolvidos. Para a explicação dessa variedade e alternância de diferentes tipos de solos no Estado, provavelmente, necessitar-se-á de estudos relacionados aos fatores, além do clima, que influenciaram a sua formação. Inicialmente, porém, é importante determinar a relação entre solos zonais e as disponibilidades climáticas no Estado.

A síntese da relação, entre solos zonais e as disponibilidades climáticas, pode ser realizada com a utilização de modelos edafoclimáticos. Esses modelos servem para verificar a relação e/ou a aproximação existente entre a variação espacial, principalmente, da temperatura e da precipitação pluvial com a distribuição dos solos. Com esse intuito, vários modelos já foram utilizados. Por exemplo, Burgos $(1969,1970)$ estudou a relação entre os tipos de solos existentes na Província de Buenos Aires e Região Nordeste da Argentina com as condições climáticas, utilizando alguns desses modelos edafoclimáticos mundialmente conhecidos.

Neste trabalho, objetivou-se determinar-se a relação entre solo e clima, no Estado do Rio Grande do Sul por meio da utilização de modelos edafoclimáticos. 


\section{Material e métodos}

A relação dos solos com as disponibilidades climáticas foi realizada por meio dos modelos edafoclimáticos de Lang (1915), Prescott (1931), Thornthwaite (1931), Aubert e Henin (1945), Thornthwaite e Hare (1955), Budyko (1956) e Kohnke et al. (1968).

No modelo de Lang (1915), foi utilizada a seguinte equação: $I_{L}=P / T$, sendo $I_{L} O$ índice de Lang (1915), P é a precipitação pluvial média dos totais anuais (mm) e T, a temperatura média anual $\left({ }^{\circ} \mathrm{C}\right)$.

No modelo de Prescott (1931), utilizou-se o índice de Meyer (1926) que relaciona a precipitação pluvial ao déficit de saturação do ar. Meyer (1926) propôs a seguinte relação: P/DS, sendo $P$ a precipitação pluvial anual em $\mathrm{mm}$ e DS é o déficit de saturação do ar em $\mathrm{mm}$ de $\mathrm{Hg}$. O déficit de saturação (DS) do vapor de água na atmosfera foi calculado pela diferença $e_{s}$ - $e_{a}$, em que $e_{s}$ e $e_{a}$ são, respectivamente, a pressão de saturação e a pressão atual do vapor de água na atmosfera $(\mathrm{mb})$. $\mathrm{O}$ valor de $\mathrm{e}_{\mathrm{s}}$, para cada estação meteorológica, foi obtido por meio da equação de Tetens (WEISS,1977): $\mathrm{e}_{s}=6,178 \exp [17,2693882 T /(T+237,3)]$, sendo T a temperatura média anual $\left({ }^{\circ} \mathrm{C}\right)$ e aquele de $e_{a}$, pela equação $e_{a}=U R \cdot e_{s} / 100$, sendo UR a umidade relativa média anual. $\mathrm{A}$ anotação $\exp \{\mathrm{x}\}$ indica $\mathrm{x}^{\mathrm{e}}$, em que $\mathrm{e}=$ 2,71828. Para o cálculo do índice de Meyer, os valores de DS foram convertidos em $\mathrm{mm}$ de $\mathrm{Hg}$.

No modelo de Thornthwaite (1931), o índice de "eficácia da precipitação" (PE) e de "eficácia térmica" (T-E) foram calculados, respectivamente, pelos coeficientes: $11,5 \mathrm{P} /(\mathrm{T}-10)^{9 / 10}$ e (T-32)/4) em que $\mathrm{P}$ é a precipitação pluvial média mensal e $\mathrm{T}$ é a temperatura média mensal $\left({ }^{\circ} \mathrm{F}\right)$. Os valores de P-E e T-E foram, respectivamente, a soma dos coeficientes dos 12 meses do ano.

Haubert e Henin (1945) aplicaram a função da drenagem e as temperaturas médias anuais para estabelecer o seu modelo edafoclimático. Estabeleceram que $\mathrm{D}$ $=\square \cdot P^{3} / 1+\square \cdot P$ e $E=P / 1+\square \cdot P^{2}$, sendo $D$ a drenagem (mm); E, a evaporação do solo (mm); P é a precipitação pluvial anual $(\mathrm{mm})$ e $\square$ é o coeficiente que varia entre valores inferiores a 5 e superiores a zero. 
No modelo de Thornthwaite e Hare (1955), foram utilizados o índice de umidade $\left(\mathrm{I}_{\mathrm{m}}\right)$ e o índice de eficiência térmica (ET), obtidos do balanço hídrico, calculado, segundo a metodologia proposta por Thornthwaite e Mather (1955), considerando o armazenamento da água disponível no solo igual a $100 \mathrm{~mm}$. A evapotranspiração potencial (ETP) foi estimada, utilizando a metodologia, segundo Thornthwaite (1945). O $I_{m}$ foi calculado por meio da equação: $I_{m}=I_{h}-0,6$ la, sendo $I_{h}$ $=100\left(\right.$ Exc/ETP) e $l_{a}=100$ (Def/ETP), em que $I_{h}, l_{a}, E T P$, Exc e Def são, respectivamente, o índice hídrico, índice de aridez, evapotranspiração potencial anual e excesso e déficit hídrico anual, em $\mathrm{mm}$.

O modelo de Budyko (1956) está fundamentado em dois índices: um hídrico e outro térmico. $O$ índice hídrico foi determinado pela relação entre o saldo anual de radiação $(\mathrm{Rn})$, a energia consumida na evaporação da precipitação pluvial média anual ( $\mathrm{Lr}$ ) e o índice térmico, pelo saldo anual de radiação do local (Rn). Esse é calculado pela equação $\mathrm{Rn}=-18,81+0,69 \mathrm{Rs}$, em que $\mathrm{Rs}$ é a radiação solar global, em cal.cm ${ }^{-2}$.ono ${ }^{-1}$ (BERGAMASCHI et al., 2003).

Kohnke et al. (1968) propuseram um modelo baseado no biofator (o quociente entre a precipitação pluvial anual e a temperatura média anual).

Os diferentes tipos de solos utilizados nos modelos edafoclimáticos foram aqueles indicados nos modelos originais. Optou-se em manter os tipos de solos, conforme constam nos modelos edafoclimáticos originais e atualizá-los na discussão dos resultados, segundo a classificação mais difundida no mundo: "Soil Taxonomy" (UNITED STATES DEPARTMENT OF AGRICULTURE, 1998). Strahler e Strahler (2005) consideram que a classificação norte-americana representa um guia global e permite estabelecer correlações entre solos de outras regiões do globo. Classifica 12 ordens de solos: Alfisols, Andisols, Aridisols, Entisols, Gelisols, Histosols, Inceptisols, Mollisols, Oxisols, Spodosols, Ultisols, Vertisols.

A classificação pedológica dos solos do Brasil consiste numa evolução do sistema Organização das Nações Unidas para a Agricultura e Alimentação (FAO, 1988), mapeados em Brasil (1973) e adaptados à nova classificação brasileira de solos realizada pela EMBRAPA (1999, 2006): Argissolos, Cambissolos, Chernossolos, Espodossolos, Gleissolos, Latossolos, Luvissolos, Neossolos, Nitossolos, Organossolos, Planossolos, Plintossolos e Vertissolos. Com exceção do 
Espodossolo, todos os outros ocorrem no Estado do Rio Grande do Sul (STRECK et al. 2002; STRECK et at. 2008).

Utilizou-se a temperatura média das médias, média das máximas e mínimas mensais e anuais do ar, a média dos totais mensais e anuais das precipitações pluviais e as médias mensais e anuais da umidade relativa do ar de 41 estações meteorológicas, pertencentes ao 8ํㅡㄹ Distrito de Meteorologia (8ํDISME), período 1931-1960 (quadro 1) e as médias anuais de radiação solar global de 25 estações meteorológicas, período 1950-1984, pertencentes à Fundação Estadual de Pesquisa Agropecuária (FEPAGRO), (quadro 2). 
Quadro 1 - Altitude e coordenadas geográficas das estações meteorológicas pertencentes ao $8^{\circ}$ DISME, cujos dados meteorológicos foram utilizadas no estudo.

\begin{tabular}{|c|c|c|c|}
\hline $\begin{array}{c}\text { ESTAÇÃO } \\
\text { METEOROLÓGICA }\end{array}$ & \begin{tabular}{|l}
$\begin{array}{l}\text { ALTITUDE } \\
(\mathrm{m})\end{array}$ \\
\end{tabular} & LATITUDE SUL & $\begin{array}{l}\text { LONGITUDE } \\
\text { OESTE }\end{array}$ \\
\hline Alegrete & 116 & $29^{\circ} 46^{\prime} 47^{\prime \prime}$ & $55^{\circ} 47^{\prime} 15^{\prime \prime}$ \\
\hline Bagé & 216 & $31^{\circ} 20^{\prime} 13^{\prime \prime}$ & $54^{\circ} 06^{\prime} 21^{\prime \prime}$ \\
\hline Bento Gonçalves & 619 & $29^{\circ} 10^{\prime} 00^{\prime \prime}$ & $51^{\circ} 25^{\prime} 00^{\prime \prime}$ \\
\hline Bom Jesus & 1047 & $28^{\circ} 40^{\prime} 10^{\prime \prime}$ & $50^{\circ} 26^{\prime} 25^{\prime \prime}$ \\
\hline Caçapava do Sul & 450 & $30^{\circ} 30^{\prime} 32^{\prime \prime}$ & $53^{\circ} 29^{\prime} 22^{\prime \prime}$ \\
\hline Cachoeira do Sul & 68 & $30^{\circ} 02^{\prime} 45^{\prime \prime}$ & $52^{\circ} 53^{\prime} 39^{\prime \prime}$ \\
\hline Caxias do Sul & 740 & $29^{\circ} 10^{\prime} 25^{\prime \prime}$ & $51^{\circ} 12^{\prime} 21^{\prime \prime}$ \\
\hline Cruz Alta & 473 & $28^{\circ} 38^{\prime} 21^{\prime \prime}$ & $53^{\circ} 36^{\prime} 34^{\prime \prime}$ \\
\hline Dom Pedrito & 140 & $30^{\circ} 58^{\prime} 57^{\prime \prime}$ & $54^{\circ} 39^{\prime} 56^{\prime \prime}$ \\
\hline Encruzilhada do Sul & 420 & $30^{\circ} 32^{\prime} 35^{\prime \prime}$ & $52^{\circ} 31^{\prime} 20^{\prime \prime}$ \\
\hline Guaporé & 450 & $28^{\circ} 55^{\prime} 44^{\prime \prime}$ & $51^{\circ} 54^{\prime} 45^{\prime \prime}$ \\
\hline Iraí & 227 & $27^{\circ} 11^{\prime} 45^{\prime \prime}$ & $53^{\circ} 14^{\prime} 01^{\prime \prime}$ \\
\hline Itaqui & 53 & $29^{\circ} 07^{\prime} 10^{\prime \prime}$ & 56³2'52" \\
\hline Jaguarão & 11 & $32^{\circ} 33^{\prime} 32^{\prime \prime}$ & $53^{\circ} 23^{\prime} 20^{\prime \prime}$ \\
\hline Julio de Castilhos & 516 & $29^{\circ} 13^{\prime} 26^{\prime \prime}$ & $53^{\circ} 40^{\prime} 45^{\prime \prime}$ \\
\hline Lagoa Vermelha & 805 & $28^{\circ} 25^{\prime} 35^{\prime \prime}$ & $51^{\circ} 35^{\prime} 51^{\prime \prime}$ \\
\hline Marcelino Ramos & 383 & $27^{\circ} 27^{\prime} 40^{\prime \prime}$ & 51054'22" \\
\hline Palmeira das Missões & 634 & $27^{\circ} 53^{\prime} 55^{\prime \prime}$ & $53^{\circ} 26^{\prime} 45^{\prime \prime}$ \\
\hline Passo Fundo & 678 & $28^{\circ} 15^{\prime} 39^{\prime \prime}$ & $52^{\circ} 24^{\prime} 33^{\prime \prime}$ \\
\hline Pelotas & 7 & $31^{\circ} 45^{\prime} 00^{\prime \prime}$ & $52^{\circ} 21^{\prime} 00^{\prime \prime}$ \\
\hline Piratini & 345 & $31^{\circ} 26^{\prime} 54^{\prime \prime}$ & $53^{\circ} 06^{\prime} 09^{\prime \prime}$ \\
\hline Porto Alegre & 10 & $30^{\circ} 01^{\prime} 53^{\prime \prime}$ & $51^{\circ} 01^{\prime} 53^{\prime \prime}$ \\
\hline Rio Grande & 8 & $32^{\circ} 01^{\prime} 44^{\prime \prime}$ & $52^{\circ} 05^{\prime} 40^{\prime \prime}$ \\
\hline Santa Cruz do Sul & 56 & $29^{\circ} 43^{\prime} 05^{\prime \prime}$ & $52^{\circ} 25^{\prime} 45^{\prime \prime}$ \\
\hline Santa Maria & 138 & $29^{\circ} 41^{\prime} 25^{\prime \prime}$ & $53^{\circ} 48^{\prime} 42^{\prime \prime}$ \\
\hline Santana do Livramento & 210 & $30^{\circ} 53^{\prime} 18^{\prime \prime}$ & $55^{\circ} 31^{\prime} 56^{\prime \prime}$ \\
\hline Santa Rosa & 360 & $27^{\circ} 51^{\prime} 50^{\prime \prime}$ & $54^{\circ} 25^{\prime} 59^{\prime \prime}$ \\
\hline Santa Vitória do Palmar & 6 & $33^{\circ} 31^{\prime} 14^{\prime \prime}$ & $53^{\circ} 21^{\prime} 47^{\prime \prime}$ \\
\hline Santiago & 426 & $29^{\circ} 11^{\prime} 00^{\prime \prime}$ & 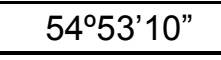 \\
\hline Santo Ângelo & 289 & $28^{\circ} 18^{\prime} 14^{\prime \prime}$ & $54^{\circ} 15^{\prime} 52^{\prime \prime}$ \\
\hline São Borja & 96 & $28^{\circ} 39^{\prime} 44^{\prime \prime}$ & $56^{\circ} 00^{\prime} 15^{\prime \prime}$ \\
\hline São Francisco de Paula & 912 & $29^{\circ} 20^{\prime} 00^{\prime \prime}$ & $50^{\circ} 31^{\prime} 21^{\prime \prime}$ \\
\hline São Gabriel & 124 & $30^{\circ} 20^{\prime} 27^{\prime \prime}$ & 5419'01" \\
\hline Soledade & 720 & $29^{\circ} 03^{\prime} 14^{\prime \prime}$ & $52^{\circ} 26^{\prime} 00^{\prime \prime}$ \\
\hline São Luiz Gonzaga & 254 & $28^{\circ} 23^{\prime} 53^{\prime \prime}$ & $54^{\circ} 58^{\prime} 18^{\prime \prime}$ \\
\hline Tapes & 5 & $30^{\circ} 50^{\prime} 00^{\prime \prime}$ & 513'00" \\
\hline Taquara & 29 & $29^{\circ} 45^{\prime} 00^{\prime \prime}$ & $50^{\circ} 45^{\prime} 00^{\prime \prime}$ \\
\hline Taquari & 76 & $29^{\circ} 48^{\prime} 15^{\prime \prime}$ & $51^{\circ} 49^{\prime} 30^{\prime \prime}$ \\
\hline Torres & 43 & $29^{\circ} 20^{\prime} 34^{\prime \prime}$ & $49^{\circ} 43^{\prime} 39^{\prime \prime}$ \\
\hline Uruguaiana & 69 & $29^{\circ} 45^{\prime} 23^{\prime \prime}$ & $57^{\circ} 05^{\prime} 12^{\prime \prime}$ \\
\hline Vacaria & 955 & $28^{\circ} 33^{\prime} 00^{\prime \prime}$ & $50^{\circ} 42^{\prime} 21^{\prime \prime}$ \\
\hline
\end{tabular}

Fonte: Instituto de Pesquisas Agronômicas (1989). 
Quadro 2 - Coordenadas geográficas das estações meteorológicas pertencentes à Fundação Estadual de Pesquisa Agropecuária (FEPAGRO) cujos dados de radiação solar global foram utilizados nos cálculos do modelo fitoclimático de Budyco (1963).

\begin{tabular}{|c|c|c|c|}
\hline \multirow{2}{*}{$\begin{array}{c}\text { ESTAÇÃO } \\
\text { METEOROLÓGICA }\end{array}$} & LATITUDE SUL & LONGITUDE OESTE & \multirow{2}{*}{$\begin{array}{c}\text { ALTITUDE } \\
\mathrm{m} \\
\end{array}$} \\
\hline & & & \\
\hline Erexim & $27^{\circ} 37^{\prime} 45^{\prime \prime}$ & $52^{\circ} 16^{\prime} 33^{\prime \prime}$ & 760 \\
\hline Santo Augusto & $27^{\circ} 54^{\prime} 16^{\prime \prime}$ & $53^{\circ} 45^{\prime} 14^{\prime \prime}$ & 380 \\
\hline Passo Fundo & $28^{\circ} 15^{\prime} 41^{\prime \prime}$ & $52^{\circ} 24^{\prime} 45^{\prime \prime}$ & 709 \\
\hline ljuí & $28^{\circ} 23^{\prime} 17^{\prime \prime}$ & $53^{\circ} 54^{\prime} 50^{\prime \prime}$ & 448 \\
\hline Vacaria & $28^{\circ} 30^{\prime} 09^{\prime \prime}$ & $50^{\circ} 56^{\prime} 12^{\prime \prime}$ & 955 \\
\hline São Borja & $28^{\circ} 39^{\prime} 44^{\prime \prime}$ & $56^{\circ} 00^{\prime} 44^{\prime \prime}$ & 99 \\
\hline Júlio de Castilhos & $29^{\circ} 13^{\prime} 26^{\prime \prime}$ & $53^{\circ} 40^{\prime} 45^{\prime \prime}$ & 514 \\
\hline Cruz Alta & $28^{\circ} 38^{\prime} 21^{\prime \prime}$ & $53^{\circ} 36^{\prime} 34^{\prime \prime}$ & 473 \\
\hline Veranópolis & $28^{\circ} 56^{\prime} 14^{\prime \prime}$ & 513'11" & 705 \\
\hline Farroupilha & $29^{\circ} 14^{\prime} 30^{\prime \prime}$ & $51^{\circ} 26^{\prime} 20^{\prime \prime}$ & 702 \\
\hline Osório & $29^{\circ} 40^{\prime} 49^{\prime \prime}$ & $50^{\circ} 13^{\prime} 56^{\prime \prime}$ & 32 \\
\hline Santa Maria & $29^{\circ} 41^{\prime} 24^{\prime \prime}$ & $53^{\circ} 48^{\prime} 42^{\prime \prime}$ & 153 \\
\hline Uruguaiana & $29^{\circ} 45^{\prime} 23^{\prime \prime}$ & $57^{\circ} 05^{\prime} 37^{\prime \prime}$ & 74 \\
\hline Alegrete & $29^{\circ} 46^{\prime} 47^{\prime \prime}$ & $55^{\circ} 47^{\prime} 15^{\prime \prime}$ & 116 \\
\hline Taquari & $29^{\circ} 48^{\prime} 15^{\prime \prime}$ & $51^{\circ} 49^{\prime} 30^{\prime \prime}$ & 76 \\
\hline Tramandaí & $29^{\circ} 56^{\prime} 22^{\prime \prime}$ & $50^{\circ} 30^{\prime} 12^{\prime \prime}$ & 3 \\
\hline Cachoeira do Sul & $30^{\circ} 02^{\prime} 45^{\prime \prime}$ & $52^{\circ} 53^{\prime} 39^{\prime \prime}$ & 68 \\
\hline Guaíba & $30^{\circ} 05^{\prime} 52^{\prime \prime}$ & $51^{\circ} 39^{\prime} 08^{\prime \prime}$ & 46 \\
\hline São Gabriel & $30^{\circ} 20^{\prime} 27^{\prime \prime}$ & $54^{\circ} 19^{\prime} 01^{\prime \prime}$ & 109 \\
\hline Quaraí & $30^{\circ} 23^{\prime} 17^{\prime \prime}$ & $56^{\circ} 26^{\prime} 53^{\prime \prime}$ & 100 \\
\hline Encruzilhada do Sul & $30^{\circ} 32^{\prime} 35^{\prime \prime}$ & $52^{\circ} 31^{\prime} 20^{\prime \prime}$ & 420 \\
\hline Santana do Livramento & $30^{\circ} 53^{\prime} 18^{\prime \prime}$ & $55^{\circ} 31^{\prime} 56^{\prime \prime}$ & 210 \\
\hline Bagé & $31^{\circ} 20^{\prime} 14^{\prime \prime}$ & $54^{\circ} 05^{\prime} 59^{\prime \prime}$ & 214 \\
\hline Rio Grande & $32^{\circ} 01^{\prime} 02^{\prime \prime}$ & $52^{\circ} 09^{\prime} 32^{\prime \prime}$ & 16 \\
\hline Jaguarão & $32^{\circ} 33^{\prime} 32^{\prime \prime}$ & $53^{\circ} 23^{\prime} 20^{\prime \prime}$ & 11 \\
\hline
\end{tabular}

Fonte: Fundação Estadual de Pesquisa Agropecuária (1989).

\section{Resultados e discussões}

No modelo de Lang (1915), figura 1, todas as estações se enquadram nas condições climáticas de solos pardos, com exceção da estação meteorológica de São Francisco de Paula, local de maior precipitação pluvial do Estado, que se ajusta às condições climáticas de solos negros. 


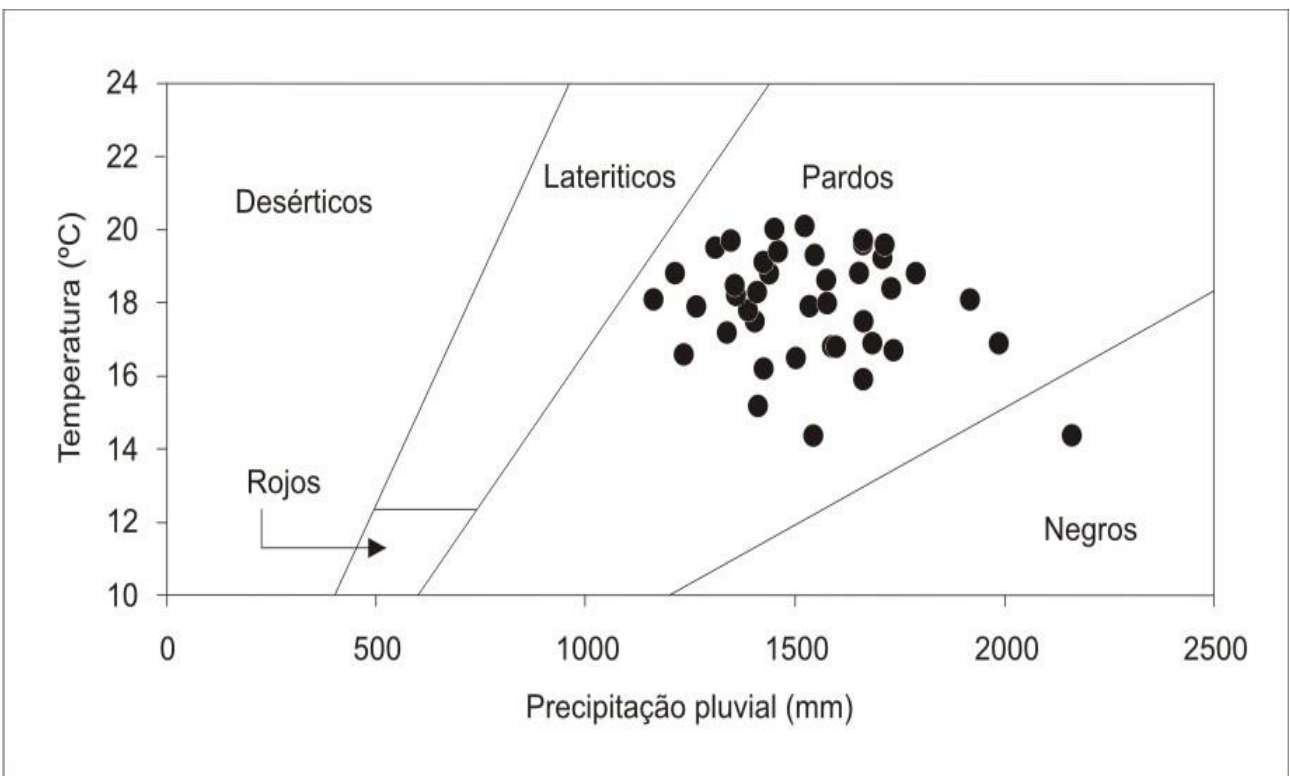

Figura 1 - Modelo edafoclimático de Lang (1915) com representação das médias anuais de temperatura e de precipitação pluvial das 41 estações meteorológicas do Estado do Rio Grande do Sul.

No modelo de Prescott (1931), figura 2, os valores médios do índice P/DS, das 41 estações meteorológicas do quadro 1, localizam-se em condições de formação de solos podzólicos.

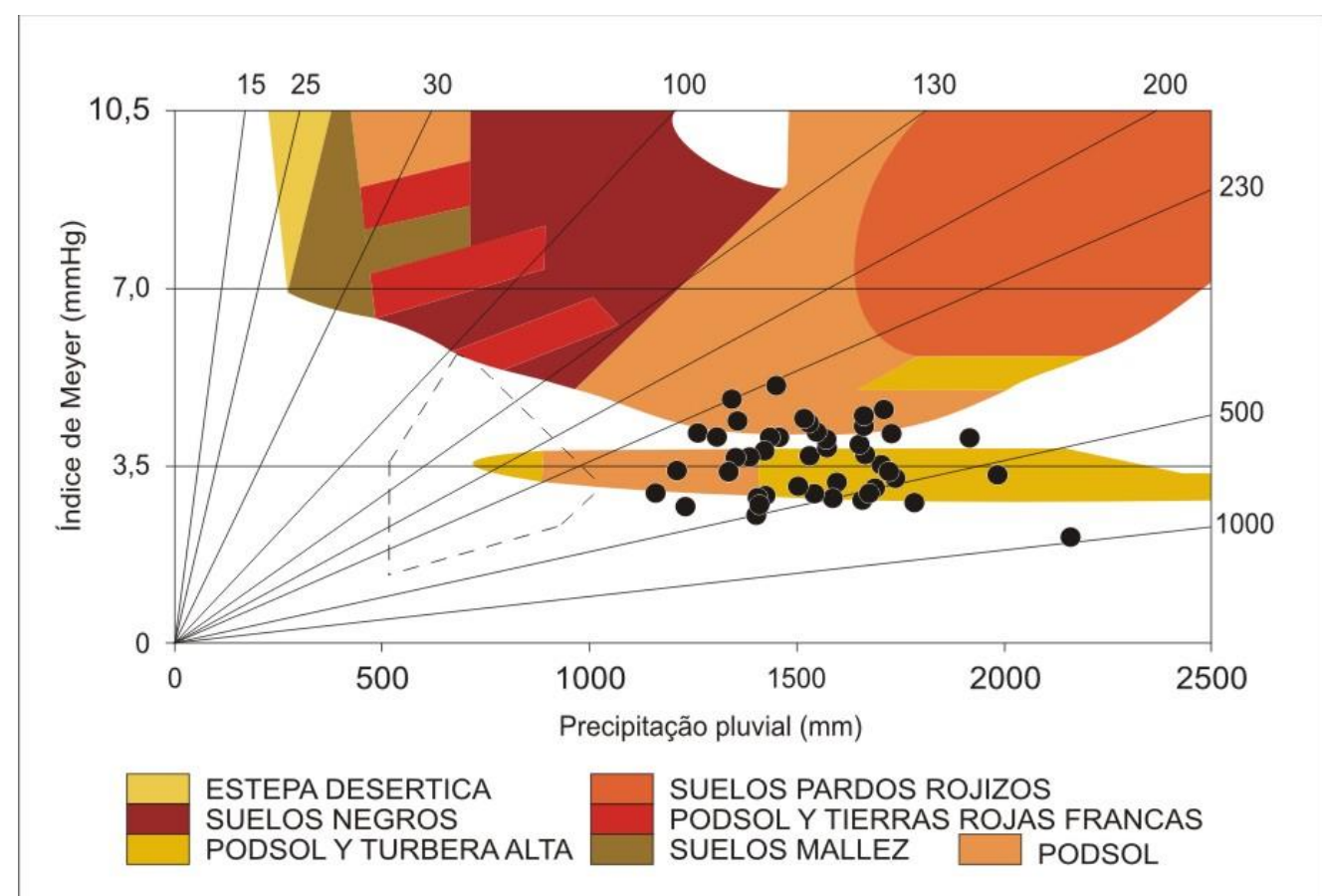

Figura 2 - Modelo edafoclimático de Prescott (1931) com representação das médias anuais de temperatura e de precipitação pluvial das 41 estações meteorológicas do Estado do Rio Grande do Sul. 
Os solos pardos são descritos também como solos castanhos e apresentam um perfil semelhante ao solo chernozem. Ocorrem entre zonas climáticas semi-áridas e subúmidas, em latitudes médias, que correspondem àquelas zonas com verões muito quentes e invernos frios. Possuem, no perfil, uma acumulação de carbonato cálcico muito endurecida, de forma que os bosques não encontram facilidades para se desenvolverem. Em geral, a vegetação natural associada aos solos pardos são do tipo pradarias e campestre. Pelo sistema de classificação dos solos, Soil Taxonomy, os solos pardos correspondem aos Mollisols e são definidos como aqueles que se formam em condições climáticas bastante variáveis, especialmente em latitudes médias, associados a regimes com moderado a pronunciado déficit hídrico estacional, do tipo semi-árido e subúmido. Alguns, porém, se formam em climas úmidos. Se comparada a distribuição desses solos com a distribuição dos climas, observa-se uma estreita relação com climas semi-áridos de latitudes médias. Sua ocorrência é indicada para várias regiões do mundo e para a América do Sul: as regiões do Pampa Argentino e do Uruguai. São descritos, detalhadamente, em sete subordens, e acentuam a característica da ocorrência de uma acumulação de carbonato cálcico no perfil. A subordem dos Ustolls são Mollisols de regime hídrico ústico, possuem um horizonte de acumulação de carbonato de cálcio que se desenvolve na profundidade entre 50 e $100 \mathrm{~cm}$. Os Mollisols estão associados, geralmente, à vegetação de pradarias. A existência de uma zona de excesso de carbonato cálcico no perfil impede a existência de uma vegetação natural de grande porte (Sthraler \& Sthraler, 2005).

No Rio Grande do Sul, pelo Sistema Brasileiro de Classificação dos Solos - SiBCS (EMBRAPA, 2006), os solos pardos mantêm semelhanças com os Chernossolos. Conforme Streck et al. (2008), ocorrem de forma esparsa em todo o território do Estado e, em áreas mais extensas, na Depressão Central. Caracterizam-se por conter razoáveis teores de material orgânico, boa fertilidade química e alta capacidade de troca catiônica (CTC) em todo o perfil. A presença de carbonatos de cálcio identifica a subordem dos Chernossolos ebánicos carbonáticos que se situam em relevos planos e suavemente ondulados. Nesses solos, a presença de argilas expansivas (esmectitas) torna-os duros, mas secos e pegajosos, quando úmidos.

O território do Rio Grande do Sul apresenta indícios que preservam testemunhos palinológicos de paleoclimas, entre eles, o clima árido e a paisagem de deserto. O clima quente e seco, devido ao aquecimento verificado na Terra, no Período Jurássico até o início do Cretáceo, da Era Mesozóica, pode ter contribuído para a formação da zona de excesso de carbonato cálcico (BIGARELLA, 1964). 
De acordo com Bigarella (1964), no período Quaternário, o Brasil meridional foi marcado por mudanças climáticas profundas e extremas, correlacionadas à flutuação do nível dos oceanos, nas quais se alternaram fases semi-áridas prolongadas (períodos glaciais) com fases úmidas (períodos interglaciais). Essas condições climáticas podem ter contribuído para a formação da excessiva dureza dos solos pardos, quando secos e à acumulação de carbonato cálcico no perfil.

No modelo de Prescott (1931), figura 2, os valores médios do índice P/DS, das 41 estações meteorológicas do quadro 1, localizam-se em condições de formação de solos podzólicos e no modelo de Thornthwaite (1931), figura 3, os valores dos índices de "eficácia da precipitação" (P-E) e de "eficácia térmica" (T-E) de todas as estações meteorológicas utilizadas se situam na zona de solos podzólicos, vermelhos e amarelos, indicando condições de solo para vegetação natural de bosques.

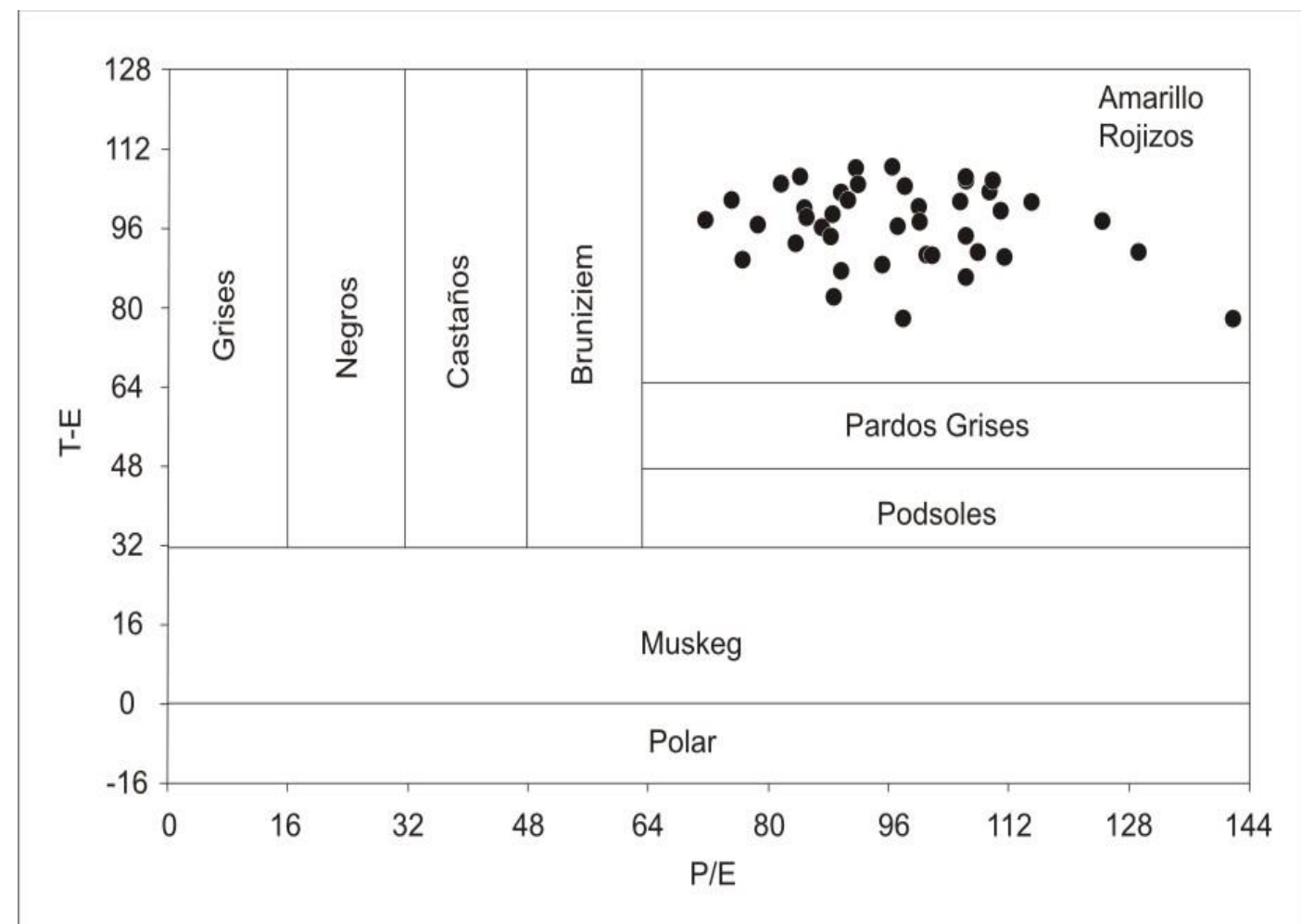

Figura 3 - Modelo edafoclimático de Thornthwaite e representação das médias anuais de temperatura e de precipitação pluvial das 41 estações meteorológicas do Estado do Rio Grande do Sul.

Os solos podzólicos são característicos de climas úmidos e associados à vegetação natural de bosques, especialmente, boreais. Sua coloração varia desde acinzentada, 
brunada, amarelada e avermelhada. A coloração vermelha e amarela é devido à oxidação do ferro. As cores vermelha e amarela, portanto, devem-se aos óxidos de ferro e indicam condições de umidade associada à boa drenagem da água das precipitações pluviais. Em geral, os perfis são de profundidade variável e neles ocorre o processo de podzolização (transporte de argila por iluviação do horizonte A para o horizonte B).

No sistema de classificação dos solos Soil Taxonomy (UNITED STATES DEPARTMENT OF AGRICULTURE, 1998), os podzólicos correspondem aos Oxisols e Ultisols. Solos com horizontes bem desenvolvidos e com minerais bastante alterados em decorrência da longa e contínua adaptação aos regimes térmicos e hídricos. Os Oxisols, normalmente, desenvolvem-se nas regiões equatoriais submetidas à climas úmidos desde o Pleistoceno ou períodos mais antigos. Ocorrem, também, em algumas regiões tropicais e subtropicais condicionadas ao regime de alternância de períodos secos e muito úmidos, durante um longo período geológico. Os Ultisols apresentam uma ampla zona de domínio em várias regiões do mundo de latitudes médias, entre elas, o sudeste dos Estados Unidos, sul da China, nordeste da Austrália, Bolívia e sul do Brasil.

Tomando-se como referência o mapa de climas do mundo, observa-se que o clima dessas áreas oscila entre subtropical úmido, subtropical, tropical seco e úmido, monçônico e tropical litorâneo. Esses climas possuem elevado excedente hídrico na estação chuvosa e amplitude térmica em relação à estação seca. A superfície dessas regiões é submetida ao intemperismo e erosão de forma que a rocha altera-se, também, em profundidade, permitindo a lixiviação. A vegetação florestal natural é arbórea, esparsa e de pequeno porte.

No Rio Grande do Sul, pelo Sistema Brasileiro de Classificação dos Solos - SiBCS (EMBRAPA, 2006), esses solos mantêm semelhanças com os Argissolos, Luvissolos e Nitossolos. Conforme Streck et al. (2008), ocorrem em relevo suave ondulado até o fortemente ondulado, ocupando, em termos percentuais, a maior parte da área territorial do Rio Grande do Sul. Apresentam baixa fertilidade natural, devido à acidez e alta saturação por alumínio e necessitam do manejo com corretivos e fertilizantes para neles se desenvolverem campo nativo ou lavoura. A vegetação natural é esparsa e de pequeno porte.

No modelo de Thornthwaite (1931), figura 3, os valores dos índices de "eficácia da precipitação" (P-E) e de "eficácia térmica" (T-E) de todas as estações meteorológicas utilizadas se situam na zona de solos podzólicos vermelhos e amarelos, indicando condições de solo para vegetação natural de bosques.

Segundo BRASIL (1973), os solos denominados podzólico vermelho-amarelo predominam em relevos altos, especialmente, formados por coxilhas e morros e são 
originados em condições de boa drenagem, não-hidromórficos. Pelo Sistema Brasileiro de Classificação dos Solos - SiBCS (EMBRAPA, 2006), esses solos são classificados como Argissolos e Luvissolos. Conforme Streck et al. (2008), os Argissolos são geralmente profundos a muito profundos, bem drenados e oriundos dos mais diversos tipos de rochas, como basaltos, granitos, arenitos e outros sedimentos. Diversos autores, entre eles, Christofoletti (1974), assinalam que rochas diferentes, quando sujeitas às mesmas condições climáticas por um longo período de tempo, darão origem, normalmente, a solos semelhantes ou quase idênticos.

No Rio Grande do Sul, esses solos foram classificados em Argissolos vermelhos e Argissolos vermelho-amarelo, de acordo com a cor que predomina no horizonte B textural. Estes últimos foram identificados a partir de três substratos: do basalto, do arenito e do granito (STRECK et al., 2008). Solos que apresentam tipicamente um perfil com um gradiente textural, em que o horizonte $B$ sempre é mais argiloso em comparação aos horizontes $\mathrm{A}$ ou $\mathrm{E}$, atestando boas condições de drenagem, de lixiviação e de percolação da água no perfil. Esses ambientes, no perfil, são condicionados, especialmente, pelo clima úmido, com as precipitações pluviais bem distribuídas durante o ano. A água que percola no perfil, promove a hidratação de constituintes e favorece a translocação dos minerais, acelerando as transformações de constituintes e, conseqüentemente, o processo evolutivo do solo.

No modelo de Aubert e Henin (1945), figura 4, igualmente, os dados de todas as estações meteorológicas do Estado indicam condições climáticas para a formação de solos dos tipos podzólicos. 


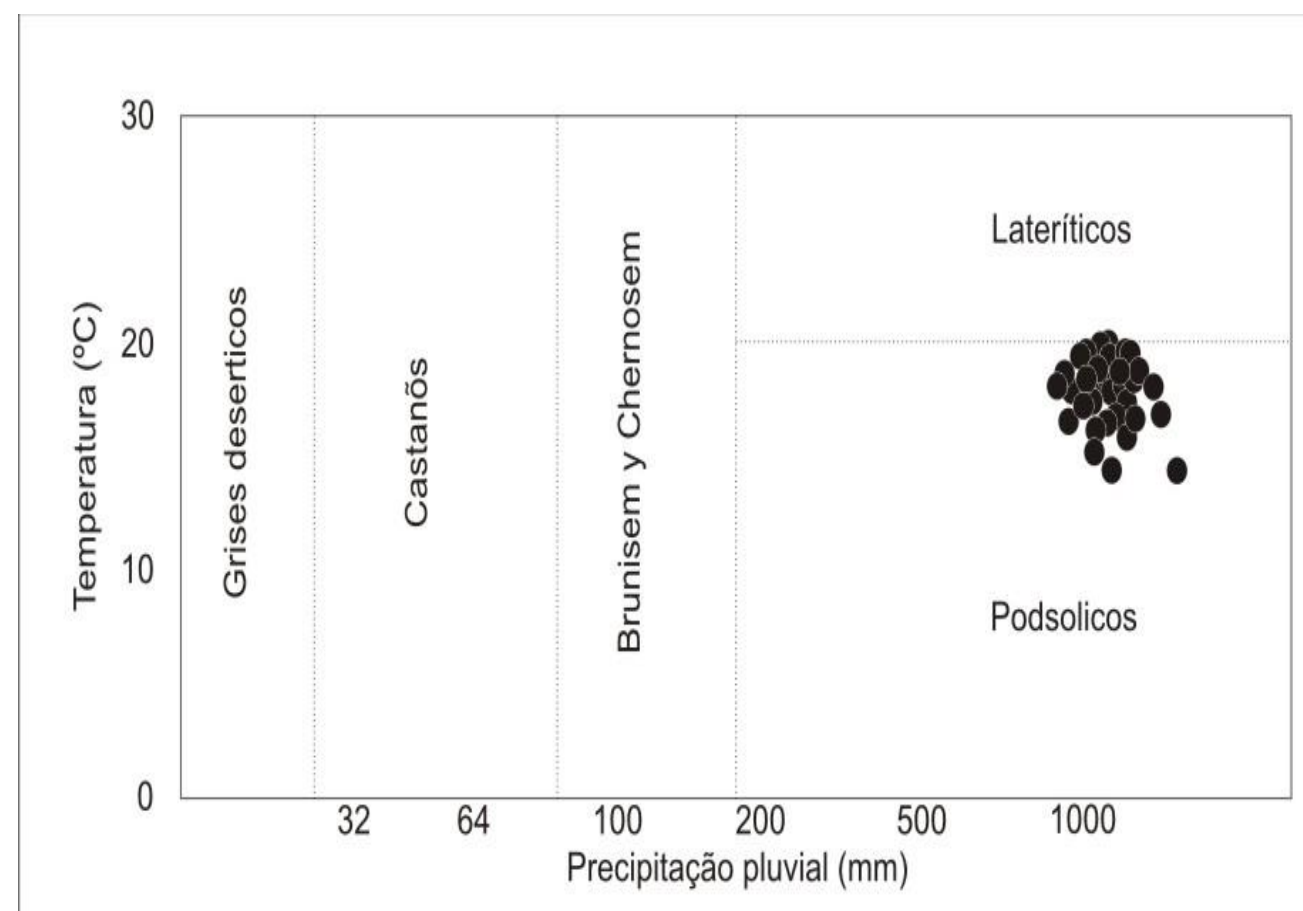

Figura 4 - Modelo edafoclimático de Aubert e Henin (1945) e representação das médias anuais de temperatura e de precipitação pluvial das 41 estações meteorológicas do Estado do Rio Grande do Sul.

O modelo de Thornthwaite e Hare (1955), figura 5, e o modelo de Budyko (1956), figura 6, também enquadram os dados de todas as estações meteorológicas do Estado em condições climáticas, característica de solos podzólico vermelho-amarelo e vegetação natural de bosques. 


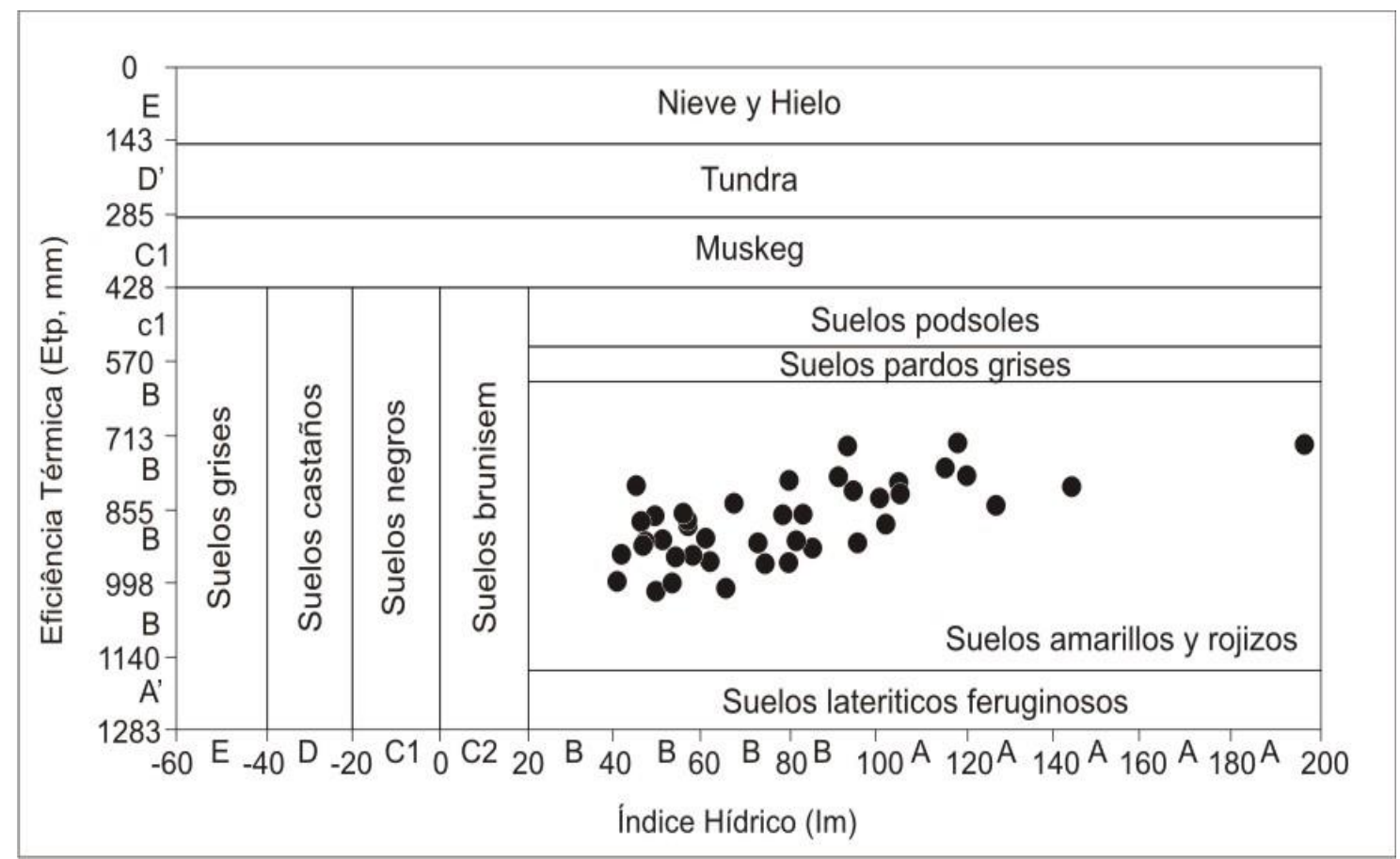

Figura 5 - Modelo edafoclimático de Thornthwaite e Hare (1955) e representação das médias anuais de temperatura e de precipitação pluvial das 41 estações meteorológicas do Estado do Rio Grande do Sul.

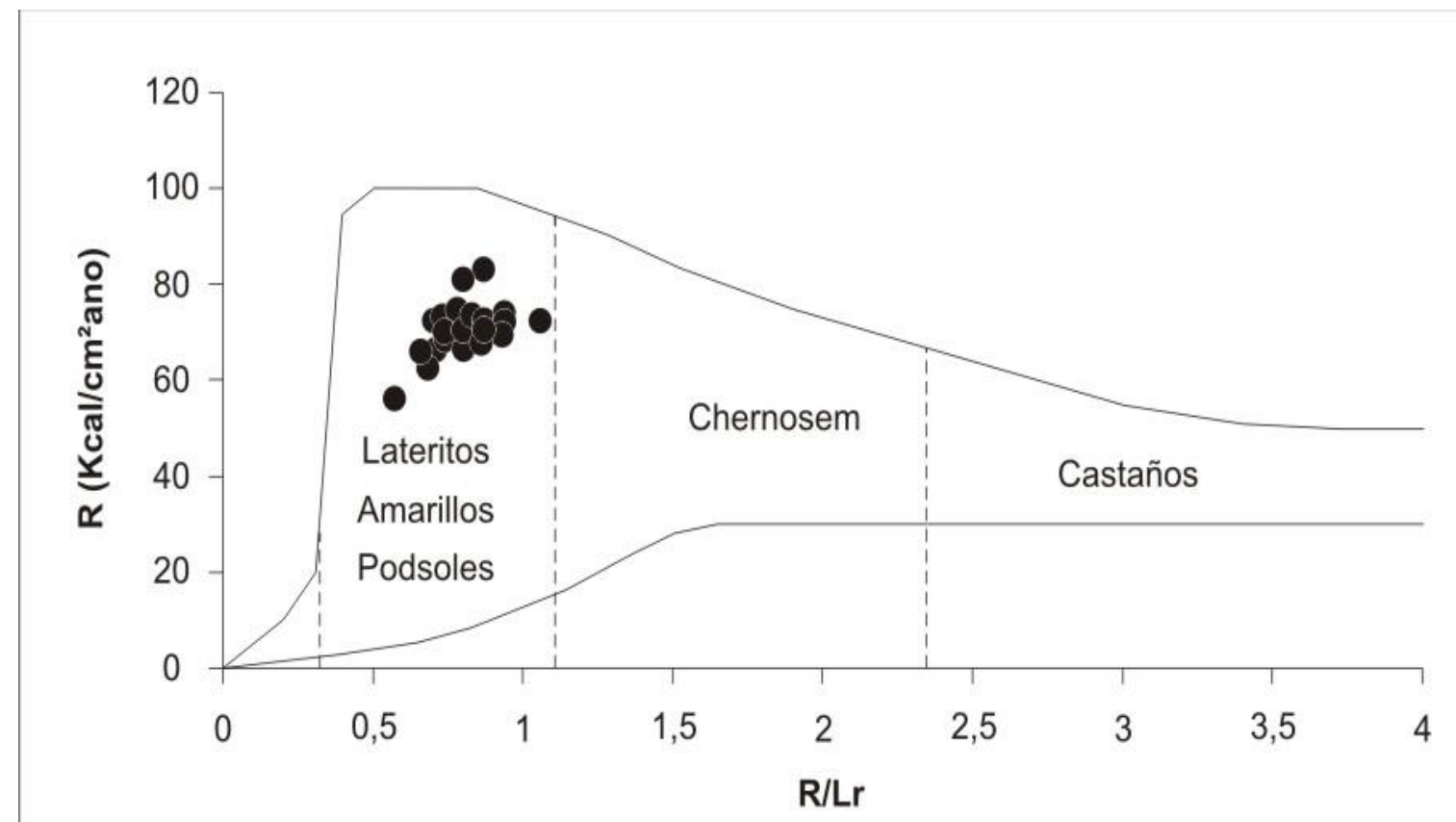

Figura 6 - Modelo edafoclimático de Budyco (1956) e representação das médias anuais de temperatura e de precipitação pluvial das 41 estações meteorológicas do Estado do Rio Grande do Sul. 
Os modelos edafoclimáticos de Prescott (1931), Thornthwaite (1931), Aubert e Henin (1945), Thornthwaite e Hare (1955) e Budyko (1956) demonstram resultados semelhantes entre si. Indicam que as condições climáticas do Estado, de temperatura e precipitação pluvial, favorecem a formação de solos podzólicos, com exceção do modelo de Lang (1915) que identifica solos pardos.

$\mathrm{Na}$ figura 7, observa-se a distribuição dos dados de temperatura e precipitação pluvial das 41 estações meteorológicas do Rio Grande do Sul no modelo edafoclimático de Kohnke et al. (1968). A maior parte das estações meteorológicas localizam-se na zona de formação de Latossolos, de podzólicos vermelho-amarelo, podzólico vermelho escuro e solos brunizems.

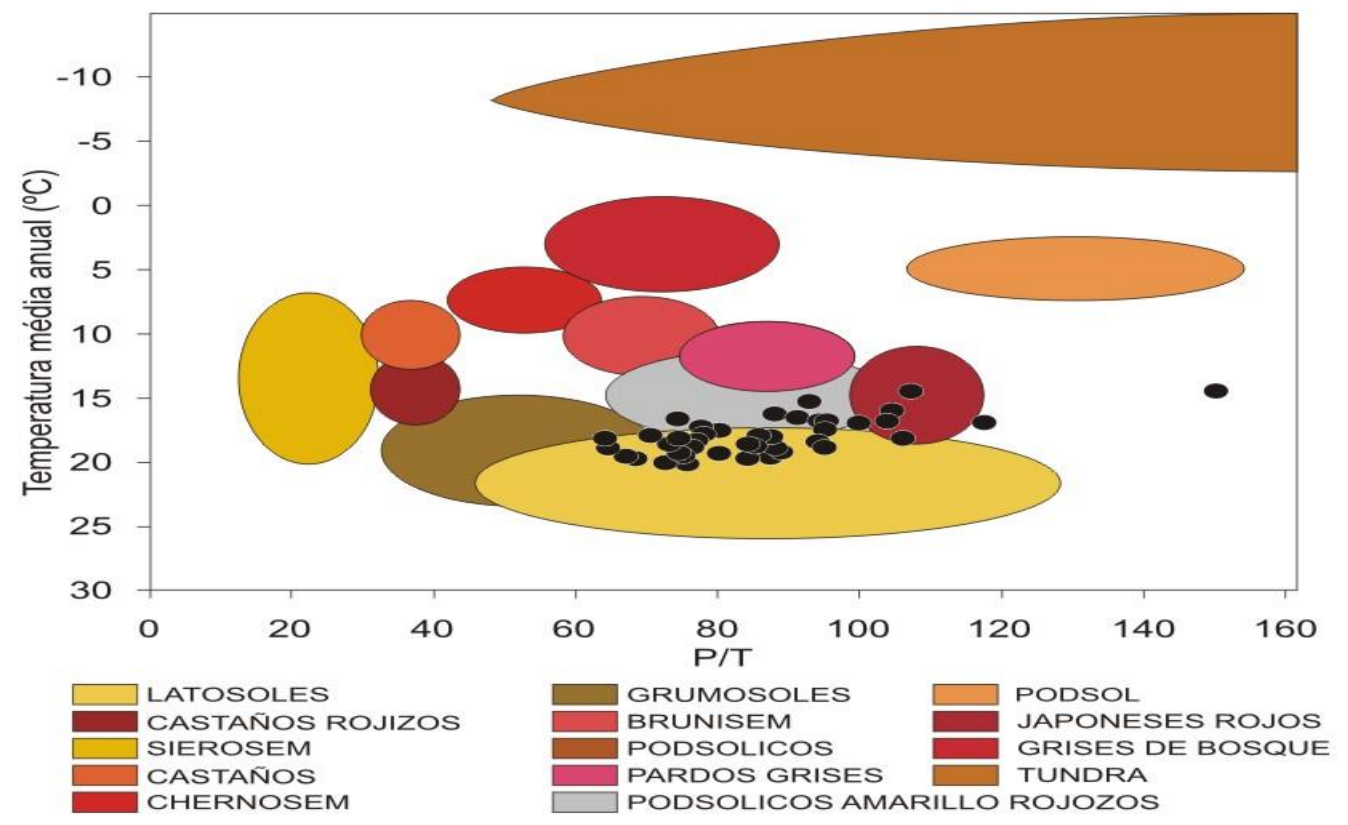

Figura 7 - Modelo edafoclimático de Kohnke (1968) e representação das médias anuais de temperatura e de precipitação pluvial das 41 estações meteorológicas do Estado do Rio Grande do Sul.

Os Latossolos, segundo Streck et al. (2008), são solos bem drenados, normalmente profundos a muito profundos, altamente intemperizados, em condições de relevo suave ondulado. Correspondem aos Oxisols e ocorrem, em regiões equatoriais e tropicais com altos índices hídricos. No Rio Grande do Sul, podem ocorrer, de forma esparsa, em todo o Estado, porém as maiores áreas estão localizadas no Planalto Norte-rio-grandense. Nessas áreas, são constituídos pelo material de origem basalto, profundamente intemperizados, têm predomínio de caulinita e óxidos de ferro, o que lhes confere baixa CTC, acentuada acidez, pouca reserva de nutrientes e toxidez por alumínio para as plantas. Os valores de 
precipitação pluvial das 41 estações meteorológicas do Estado, representadas no quadro 1, favorecem o intemperismo e a formação de caulinita e de óxidos de ferro, características encontradas no Latossolo. Os resultados obtidos nos modelos edafoclimáticos utilizados, tanto os baseados em índices que relacionam à precipitação pluvial com a temperatura do ar, como aqueles de Lang (1915), Prescott (1931) e Kohnke (1968), figuras 1, 2 e 7, respectivamente ou naqueles fundamentados na relação entre as condições hídricas do solo e térmicas do ar, como os de Thornthwaite (1931), Haubert e Henin (1945), Thornthwaite e Hare (1955), figuras 3, 4 e 5, respectivamente ou, ainda, aquele baseado na relação entre o saldo anual de radiação e a energia consumida na evaporação da precipitação pluvial média anual, como no modelo de Budyko (1956), figura 6, não expressam a realidade das condições de distribuição geográfica dos atuais tipos de solos do Estado, em que existem várias regiões com solos rasos, pouco desenvolvidos e encontrados nas mais diversas condições de relevo e drenagem e, geograficamente, dispostas de forma muita heterogênea no Estado.

No Estado do Rio Grande do Sul, há a diversidade de doze tipos de solos (Streck et al., 2008) e a presença de solos jovens ou com perfis pouco desenvolvidos e rasos, a exemplo dos Gleissolos, Luvissolos, Neossolos, Organossolos, Planossolos, Plintossolos, Vertissolos. Outros caracterizam-se como medianamente rasos a profundos como Cambissolos e Chernossolos. Os Argissolos, Latossolos e Nitossolos apresentam perfis profundos a muito profundos e são aqueles que correspondem aos tipos de solos indicados nos modelos edafoclimáticos, considerando as condições de temperatura e precipitação pluvial, com exceção para o modelo de Lang (1915) que indica Chernossolos.

Assim, os resultados obtidos nos modelos edafoclimáticos aqui utilizados caracterizam condições climáticas para a formação de solos de climas úmidos. Nessas condições, os solos apresentam condições de intemperismo e lixiviação em profundidade, favorecendo a formação de perfis homogêneos, bem desenvolvidos e profundos, o que condiz com as regiões do Estado abrangidas pelos Argissolos, Latossolos e Nitossolos. Considerando que, no Estado, os Latossolos são formados a partir de diferentes litologias, pode-se afirmar que o clima é o fator determinante no intemperismo e tem grande influência na formação desses solos. 


\section{Considerações finais}

A temperatura do ar e a precipitação pluvial do Rio Grande do Sul condicionam a ocorrência de solos profundos e bem drenados e determinam a formação de Latossolo, Chernossolo, Argissolo e Nitossolo.

As condições climáticas de temperatura do ar e de precipitação pluvial vigentes no Rio Grande do Sul não expressam a realidade das condições de distribuição geográfica dos atuais tipos de solos do Estado.

\section{Referências}

AUBERT, G.; HENIN, S. Relations entre lê drainage, la température et l'évolution des sols. C. R. Acad. Sci., Paris, p. 330-332. 1945.

BERGAMASCHI, H. et al. Clima da Estação Experimental da UFRGS (e região de abragência). Porto Alegre, UFRGS, 2003. 77 p.

BIGARELLA, J. J. Variações climáticas no Quaternário e suas implicações no revestimento florístico do Paraná. Bol. V.2, no 1, p. 376-394. 1964.

BRASIL. Levantamento de reconhecimento dos solos do Rio Grande do Sul. Ministério da Agricultura. Departamento Nacional de Pesquisa Agropecuária. Divisão de Pesquisa Pedológica. Recife, 1973. 431 p. (Boletim Técnico no 30).

BUDYKO, M. I. Atlas tieplobogo balansa zemnogo shara.(Atlas do balanço calórico do globo terrestre). 69 mapas e textos, Moscou. 1956.

BUENO, M. E. T. Solo e clima: uma introdução ao estudo de suas relações. Revista Geografia e ensino. Belo Horizonte: UFMG. v. 2, no 6, p. 3-11. 1984.

BURGOS, J. J. El clima de la Provincia de Buenos Aires en relación con la vegetación natural y el suelo. In CABRERA, A. L. Flora de la Província de Buenos Aires. Buenos Aires: INTA, p. 33-39. 1969.

BURGOS, J. J. El clima de la Región Noreste de la Republica Argentina en la relación con la vegetación natural y el suelo. Boletín de la Sociedad Argentina de Botânica. Buenos Aires, v. 11, p. 37-102. 1970.

CHRISTOFOLETTI, A. Geomorfologia. São Paulo: Edgard Blücher. 1974. 149 p. 
DREW, D. Processos interativos homem-meio ambiente. Rio de Janeiro: Bertrand Brasil, 2002. 224 p.

EMBRAPA. Sistema Brasileiro de Classificação de Solos. Rio de Janeiro: Embrapa solo. 1999. 412 p.

EMBRAPA. Sistema Brasileiro de Classificação de Solos. Rio de Janeiro: Embrapa solo, 2006. 306 p.

ESTADOS UNIDOS. Keys to soil taxonomy, 5 ed. Blacksburg: Department of Agriculture. Soil Survey Staff., Pocahontas Press, 1992. 556 p. (SMSS Technical Monograph, 19).

FUNDAÇÃO ESTADUAL DE PESQUISA AGROPECUÁRIA. Atlas agroclimático do Estado do Rio Grande do Sul. Porto Alegre: Secretaria Agricultura e Abastecimento. 1989.

INSTITUTO DE PESQUISAS AGRONÔMICAS. Atlas agroclimático do Estado do Rio Grande do Sul. Porto Alegre: Secretaria da Agricultura e Abastecimento. 1989, 102p. (V 1).

JENNY, H. Factors of soil formation. New York: McGraw-Hill, 1941. 281 p.

KOHNKE, H.; STUFF, L. R,; MILLER, P. A. Quantitative relations between climate and soil formation. Journal Paper, no 3199, Lafayette, Indiana, EUA, Purdue University Agricultural Experiment Station, p. 24-33. 1968.

KÖPPEN, W. Climatologia. México: Fundo de Cultura Econômica, 1948. 466p.

KUINCHTNER, A.; BURIOL, G. A. Clima do Estado do Rio Grande do Sul segundo a classificação climática de Köppen e Thornthwaite. Disciplinarium Scientia, Santa Maria, V. 2, nr. 1, p. 171-182. 2001.

LANG, R. Versuch eiver exakten Klassifikation der böden in Klimatischer und geologischer Hinsicht. Internat Mitt. für Bdenkunde. Stuttgar, n. 8, v. 7, p. 312346. 1915.

MEYER, A. Über einige Zusammenhänge zwichen Klima und Boden in Europa. Chemie der Erde, 2. 1926.

MORENO, J. A. Clima do Rio Grande do Sul. Porto Alegre: Secretaria da Agricultura, $1961.38 \mathrm{p}$.

ORGANIZAÇÃO DAS NAÇÕES UNIDAS PARA A AGRICULTURA E ALIMENTAÇÃO - FAO. Soil map of the World. Revised legend. World Resources Report 60, FAO - Rome. Wageningem, ISRIC. 1988. 137 p. (ISRIC Technical paper, 20). 
PRESCOTT, J. A. The soils of Australia in relation to vegetation and climate. Comm. of Australia. Counc. For Scientific and Insdustrial Research.

Melbourne.1931. (Bull. nำ52).

STRECK, E. V. et al. Solos do Rio Grande do Sul. Porto Alegre: UFRGS. 2002.

STRECK, E. V. et al. Solos do Rio Grande do Sul. Porto Alegre: UFRGS. 2008.

STRAHLER, A. N.; STRAHLER, A. N. Geografia Física. Barcelona: Omega, 2005.

TEIXEIRA, W. et al. Decifrando a Terra. São Paulo: Oficina de textos. 2003.

THORNTHWAITE, C. W. The climates of North according to a new classification. The Geographical Review, Oct., p. 633-655.1931.

THORNTHWAITE, C. W.; HARE, F. K. Climate classification in forestry. Unasylva, v. 9, n. 2. 1955 (Publ. FAO, Roma).

THORNTHWAITE, C. W.; MATHER, J. R. Water balance. Climatology. Centerton, New Jersey, v. 8, n. 1, p. 1- 104. 1955.

UNITED STATES DEPARTMENT OF AGRICULTURE. Keys to soil taxonomy, 8 ed. Blacksburg: Department of Agriculture. Soil Survey Staff., Pocahontas Press, 1998. 556 p. (SMSS Technical Monograph, 19).

Soils and men: yearbook of agriculture. Washington: Washington D.C., Government Printing Office, 1998. 281 p.

WEISS. A. Algoritms for the calculation of moist air properties on a hand calculator. Transactions of ASAE, 1113-1136. 1977. 